\title{
Coronavirus Disease 2019 (COVID-19): Future Challenges and Recommendations for Dental Settings
}

\section{NAJMUS SAHAR, PRADEEP TANGADE², VIKAS SINGH³, SURBHI PRIYADARSHI ${ }^{4}$, DEBASHIS ROY*1}

The novel coronavirus outbreak is a contagious disease affecting the countries around the world. The quick advancing nature of pandemic has gripped the entire community making it a public health emergency. Infection control preventive measures are necessary to prevent it from further spreading. Medical practitioners, health care workers and Dentists are at high risk of acquiring and transmission of infection. The virus transmission occurs through respiratory tract, aerosols and droplets. Clinical manifestations of virus vary from mild to severe sickness. This review article mainly emphasizes on all the information collected to date on the virus, and future recommendations for dental settings to manage the further spread of this virus.

KEYWORDS: Coronavirus, Covid-19, Transmission, Infection Control

\section{INTRODUCTION}

A novel coronavirus Covid-19 pandemic has emerged as emergency public health crisis across the world. On $30^{\text {th }}$ January 2020 , it was declared as community health emergency of international concern, with high risk to many countries. ${ }^{1}$ The emergence of first case was found in Wuhan city, China in December. COVID -19 is also known as SARS Cov-2. Coronavirus are single stranded RNA genome with virus evolved around. The virus is found in nasopharyngeal secretions and salivary secretions of the affected patients.

Due to the widespread transmission of this virus, healthcare workers, dentists are at increased risk of contamination, being the potential carriers for the disease. ${ }^{2}$ Dental health care personnel are at very high risk as dentist deal with proximity to the mouth of the patient. Dental setups are more prone to risk of infection due to aerosol production. Therefore, this article emphasizes the upcoming challenges and recommendations for dental setups.

\section{WHAT IS COVID-19?}

Recent studies have reported that Coronavirus is similar to Severe Acute respiratory Syndrome and Middle east Respiratory syndrome. But it has been reported that SARSCov-2 has its origin from Chinese horseshoe bats. It affects mainly upper respiratory tract system in humans. ${ }^{3}$ Its structure resembles to crown like appearance when viewed under electron microscope. It is positive stranded RNA virus with 6o$140 \mathrm{~nm}$, spherical in shape.

\section{MODE OF TRANSMISSION}

The possible mode of transmission is mainly respiratory droplets, airborne contact, aerosol transmission, close contact with the patient. However the risk of vertical transmission (from mother to fetus) is yet to be confirmed. ${ }^{4}$

\section{SOURCE OF TRANSMISSION}

It has been noticed that symptomatic patients as well as asymptomatic patients are the carriers for transmission of disease. Some of the studies suggested that there is human to human transmission. ${ }^{1}$ It has been found that person to person transmission occurs via respiratory droplets (airborne spread).

\section{INCUBATION PERIOD}

The average incubation period of covid-19 virus varies from o to 14 days. The chances of transmission of virus has raised currently in asymptomatic individuals, so duration of medical observation and quarantine ranges to 14 days in case of any history of travel or contact with exposed patients. ${ }^{5}$

\section{HIGH RISK OF ACQUIRING INFECTION}

People who are at high risk of acquiring infection are generally health care workers including dentists. All age groups are susceptible but people who are at old age, immunocompromised patients, cardiovascular diseases are at more risk with poor prognosis.

\section{CLINICAL PRESENTATION}

The most common symptoms of COVID-19 virus 
include fever, cough, fatigue, shortness of breath whereas less common symptoms are headache, diarrohea, vomiting. Some of the studies revealed that CT tomography revealed bilateral pneumonia, with ground glass opacity. 5

\section{ORAL MANIFESTATIONS}

The CDC has suggested that loss of sensation/taste is an early symptom of COVID-19. Other manifestations include ulcerations, xerostomia, fungal infections, gingivitis.

\section{COVID-19 AND SALIVA}

The most effective and common way for diagnostic confirmation from the individuals is collection of throat swab. ${ }^{1}$ Though, this effects the eosophageal lining by inducing bleeding and also sometimes cause coughing which may lead to higher risk incidence for health care workers or professionals. So, now a days collection of saliva is also a preferred method and is more acceptable as it is not invasive and reduces the risk of transmission to health care workers. ${ }^{2}$ Saliva from the suspected individuals can be collected by saliva swabs or directly from salivary gland duct. Thus, saliva also plays a major role in collection of the sample for the diagnostic purpose.

\section{INFECTION CONTROL \& RECOMMENDATIONS FOR THE CONTROL OF SPREAD OF COVID 19}

There are many protocols and preventive measures that are given by the DCI to control the spread of Covid 19 Virus. ${ }^{1}$ The Dental Council of India has divided the protocols and control measures into three different phases:

\section{Phase I: Preparatory phase for a dental clinic:}

\section{FOR DOCTORS \& HEALTH CARE WORKERS}

Hydroxychloroquine Prophylaxis: All the healthcare workers who were involved in treatment or contact of asymptomatic or confirmed cases of Covid -19 are advised to go for hydroxychloroquine prophylaxis.

Training of the Health Care Workers: All the members working in hospitals, operatory areas or dental clinics are advised to maintain social distance and use masks. ${ }^{6}$ Not only this, they should also make sure all the other members entering the clinic premises should follow the rules of social distancing and must wear masks.

- Health care workers should always choose the proper PPE kit.

- The working rotation hours or the intervals to work in the operatory area should be more frequent. One should not be posted for long working hours to prevent fatigue and tiredness.

- Personal clothing should be avoided and all surgical attires should be worn.

\section{DONNING \& DOFFING OF PPE (Figure 1) DONNING OF PPE}

- Remove any accessories that you are wearing like watches, jewellery, rings etc.

- Use washroom before donning.

- Wear glasses after wearing the surgical N95 mask.

\section{DOFFING OF PPE (Figure 1) \\ FOR PATIENTS AND PATIENT'S ASSISTANTS}

All should be encouraged to wear masks and follow the instructions of social distancing.

Touching the surfaces and holding onto the railings should be avoided.

\section{THE OPERATORY AREA AND WAITING AREA}

1. Clinic entrance, waiting area and reception: At the reception area plastic or glass barriers should be installed.7 Cashless or contactless payment methods should be preferred. Posters can be used to alert the patients about coughing etiquettes, respiratory hygiene and social distancing.

2. Changing room: Should be provided for donning and doffing of PPE kits and also for changing clothes.

3. Area for sterilization: An assistant should be assigned for proper sterilization and packing of the instruments. He should also make sure sufficient availability of PPE kits and their proper storage.

4. Washrooms: Sensor taps should be used. Instead of using towels, paper towels or tissue papers should be used.

5. Dental clinic: Surfaces should be cleaned after every visit of the patient and also proper sterilization of instruments used in the operatory area should be done. In the areas of centralized ACs, return air vents should be blocked and also the windows and doors 
Selection of PPE

choose the right and proper PPE kit in terms of size and comfort.
Hand Sanitization

Before putting on the gown it is advised to sanitize your hands using hand sanitizers.
Wearing the gown

All the knots of the gown should be tied properly. If needed, help from assistant should be taken.

Face shield/ goggles used to keep the

gloves should be worn such that there's no space between the cuffs of the gown and the gloves. respirator in place and also to protect the eyes.
Use of N95 filtering facepiece respirator or face mask

Used for proper respiration and breathing.

\section{DOFFING OF PPE:}

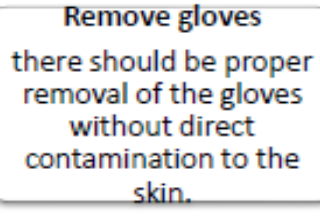

Remove gloves

there should be proper removal of the gloves

without direct contamination to the skin.

\section{Remove gown}

all the knots should be untied with the help of assistant or can also be broken off.

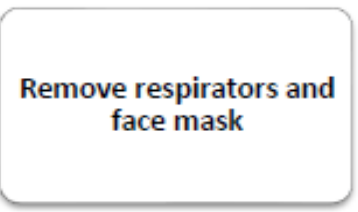

Hand hygiene

proper hand sanitization should be done before touching the face mask or shield

Remove face shields or goggles

should be removed and discarded off.

Figure 1. Procedure for Donning and Doffing of PPE

should be kept slightly open to ensure ventilation. Indoor portable air cleaning system should be used along with HEPA filters.

\section{Environment and surface disinfection: Floors} should be disinfected by $1 \%$ sodium hypochlorite. Electronic instruments should be wiped with alcohol based rub/sprit

\section{Phase II: Implementation phase}

Teleconsultation tele-screening: Screening using telephonic communication should be encouraged and also installation of Arogya setu app should be made mandatory. ${ }^{8}$
Dental history and remote triage: Screening and consultations can also be done using mobile apps. Only the pre-appointed patients should be allowed to enter the clinic areas until and unless there's case of emergency. ${ }^{9}$

Patient handling: Non- aerosol generating procedures should be encouraged along with the use of rubber dams. Proper precautions with use of face masks and PPE kits should be encouraged. All infection control measures should be taken and it is also advisable to use 4-handed technique during operative procedures. ${ }^{7}$ 
Patient discharge protocol: Drape of the patient should be removed by the assistant and should be discarded with proper care. Patient should be provided with all the follow up instructions and also instructed to perform hand sanitization. ${ }^{10}$

Disinfection protocols: All the used instruments should be immediately rinsed in running water and repeatedly touched surfaces like three way syringes, water outlets should be flushed using disinfectant solution. Hand piece should be cleaned using hand piece cleaning solutions. Floors and chairs should be cleaned. ${ }^{11}$

\section{CLINIC CLOSURE PROTOCOLS}

Fogging: 'No touch surface disinfection' The commercially available hydrogen peroxide is $11 \%(\mathrm{w} / \mathrm{v})$ solution which is stabilized by $0.01 \%$ of silver nitrate. A $20 \%$ working solution should be prepared. The volume of working solution required for fogging is approximately $1000 \mathrm{ml}$ per 1000 cubic feet. After the procedure has been completed in the operatory (in case of no negative pressure), exit the room and close the operatory for half hour for the aerosols/droplets to settle down. ${ }^{8}$ Perform the 2 Step surface cleaning followed by fogging. The fogging time is usually 45 minutes followed by contact time/dwell time of one hour. After that the room can be opened, fans can be switched on for aeration. Wet surfaces can be dried/cleaned by using a sterile cloth or clean cloth.

Protocol for health care workers on reaching home: On reaching home the shoes should be removed, clothes should be changed, mobile wristwatch etc. should be disinfected.

\section{Phase III: Patient follow up \& review}

The patients should be communicated using phone calls within next 24 hours and also in next week to make sure they have developed any symptoms so that the health care workers can take required measures. ${ }^{12}$

\section{CONCLUSION}

Coronavirus has given dentists a new challenge to deal with the patients. Transmission of virus in dental environment usually occours through aerosol, droplets. ${ }^{13}$ Dentists should be aware about the new information about the disease. Teledentistry is found to be effective in reducing the risk of infection. It is of utmost responsibility of every health care professional to strictly implement infection control protocol to combat the future challenges and further spread of infection.

\section{REFERENCES}

1. Meng L, Hua F, Bian Z. Coronavirus Disease 2019; Emerging and Future Challenges for Dental and Oral Medicine. Journal of Dental Research 2020;99(5):4817. https://doi.org/10.1177/0022034520914246

2. Kumar G A, Mohan R, Prasad Hiremutt DR, Vikhram K B. COVID-19 pandemic and safe dental practice: Need of the hour. J Indian Acad Oral Med Radiol https://doi.org/10.4103/jiaomr.jiaomr_8o_20 2020;32:164-71. 3. Bhanushali P, Katge F, Deshpande S, Chimata VK, Shetty S, Pradhan D. COVID-19: Changing Trends and Its Impact on Future of Dentistry. International Journal of Dentistry 2020; 2020: 8817424.

https://doi.org/10.1155/2020/8817424

4. Fallahi HR, Keyhan SO, Zandian D, et al. Being a front-line dentist during the Covid-19 pandemic: a literature review. Maxillofac Plast Reconstr Surg. 2020;42:12. https://doi.org/10.1186/s40902-020-002565

5. Deepika, Nagpal AK, Paul R. Infection Control in Endodontics During COVID Era: A Review. Int Healthc Res J. 2020;4(9):RV1-RV6. https://doi.org/10.26440/IHRJ/0409.12316

6. Guo YR, Cao QD, Hong ZS, Tan YY, Chen SD, Jin HJ, et al. The origin, transmission and clinical

therapies on coronavirus disease 2019 (COVID-19) outbreak - an update on the status. Mil Med Res. 2020; 7: 11. https://doi.org/10.1186/s40779-020-00240-o

7. Banakar M, Lankarani KB, Jafarpour D, Moayedi S, Banakar MH, Sadeghi AM. COVID-19 transmission risk and protective protocols in dentistry: a systematic review. BMC Oral Health 2020;20:275. https://doi.org/10.1186/s12903-020-01270-9

8. Spagnuolo G, Vito DD, Rengo S, Tatullo M. COVID19 Outbreak: An Overview on Dentistry. Int J Environ Res Public Health. 2020;17(6):2094. https://doi.org/10.339o/ijerph17062094.

9. Izzetti R, Nisi M, Gabriele M, Graziani F. COVID-19 Transmission in Dental Practice: Brief Review of Preventive Measures in Italy. Journal of Dental Research 2020;99(9):1030-8. https://doi.org/10.1177/0022034520920580

10. Zhu N, Zhang D, Wang W, Li X, Yang B, Song J, et al. A novel coronavirus from patients with pneumonia in China, 2019. N Engl J Med. 2020;382:727-33. https://doi.org/10.1056/NEJMoa20o1017

11. Peng X, Xu X, Li Y, Chen L, Zhou X, Ren B, et al. Transmission routes of $2019-\mathrm{nCoV}$ and controls in 
dental practice. Int J Oral Sci. 2020;12:9. https://doi.org/10.1038/s41368-020-0075-9

12. Chan JF, Yuan S, Kok KH, To KK, Chu H, Yang J, et al. A familial cluster of pneumonia associated with the 2019 novel coronavirus indicating person-to-person transmission: A study of a family cluster. Lancet

\begin{abstract}
2020;395:514-23. https://doi.org/10.1016/So1406736(20)30154-9

13. Zhang J, Wang S, Xue Y. Fecal specimen diagnosis 2019 novel coronavirus-infected pneumonia. J Med Virol. 2020; 92:

680-2.
\end{abstract}

Source of support: Nil, Conflict of interest: None declared

Cite this article as:

Sahar N, Tangade P, Singh V, Priyadarshi S, Roy D. Coronavirus Disease 2019 (COVID-19): Future Challenges and Recommendations for Dental Settings. Int Healthc Res J. 2021;4(11):RV1-RV5. https://doi.org/10.26440/IHRJ/0411.02392

\section{AUTHOR AFFILIATIONS: (*Corresponding Author)}

1. Post Graduate Student ( $3^{\text {rd }}$ Year)

2. Professor \& Head

3. Reader

4. Post Graduate Student ( $2^{\text {nd }}$ Year)

Department of Public Health Dentistry, Teerthanker Mahaveer Dental college and Research Centre, Moradabad, India 